\title{
Research on the Propagation Law of Stress Wave in Rock Mass Supported by Bolt under Dynamic Load
}

\author{
Feng Chen $\mathbb{D}^{1}{ }^{1}$ Xue-bin Wang, ${ }^{2}$ and Jun-guang Wang ${ }^{1}$ \\ ${ }^{1}$ School of Mechanics and Engineering, Liaoning Technical University, Fuxin, Liaoning 123000, China \\ ${ }^{2}$ Institute of Computational Mechanics, Liaoning Technical University, Fuxin, Liaoning 123000, China \\ Correspondence should be addressed to Feng Chen; cflucky@sina.cn
}

Received 21 November 2021; Revised 27 December 2021; Accepted 31 December 2021; Published 25 January 2022

Academic Editor: Yu Wang

Copyright (c) 2022 Feng Chen et al. This is an open access article distributed under the Creative Commons Attribution License, which permits unrestricted use, distribution, and reproduction in any medium, provided the original work is properly cited.

At present, the development of bolt support technology is in the ascendant period, which is of great significance to promote the development of geotechnical engineering. The numerical simulation software RFPA (Rock Failure Process Analysis) has been used to analyze the reinforcement effect of bolt on deep surrounding rock under dynamic load and conduct a comprehensive research on the force state of bolt. The characteristics of stress and displacement change in rock mass and bolt caused by stress wave are compared when the surrounding rock of underground chamber is supported with bolt or not. Numerical experimental results show that, under the action of dynamic load, the high stress area in surrounding rock can be transferred to the interior of rock mass by adding bolt to the surrounding rock of a high ground stress underground chamber, and the displacement value of each segment of bolt is basically the same. Moreover, the acoustic emission (AE) energy and AE count released by surrounding rock have been able to be reduced, and the force pattern of surrounding rock has been changed.

\section{Introduction}

The surrounding rock of a deep underground chamber is in a relatively high initial stress state, it is also subject to disturbances caused by dynamic loads such as mechanical excavation, blasting, and rock burst [1-3]. The dynamic disturbance under the condition of high ground stress easily causes the sudden instability of the surrounding rock of the underground chamber, and the application of bolt to strengthen the rock mass can give full play to the stability of rock mass itself [4-7]. This is a kind of reinforcement technology with little disturbance to the original rock, fast construction speed, safety, and reliability. The reinforcement technology has been widely used in water conservancy and hydropower, railway transportation, mining engineering, and other industries [7]. The development and application of bolt support technology is an important symbol of modern geotechnical engineering.

At present, many scholars have conducted a lot of research on the mechanical response of bolt and surrounding rock under the action of external force and have also achieved rich results. Pytlik [8] presented the methodology and results of single shear tests of bolt rods under dynamic impact loading generated by means of a drop hammer. Fahimifar and Ranjbarnia [9] pointed out that decreasing rockbolt spacing increases the support system stiffness rather than preloading of them. Liu et al. [10] investigated the bolt mechanical and energy characteristics using a $50 \mathrm{~mm}$ rod diameter split Hopkinson pressure bar (SHPB) test device. Carranza-Torres [11] demonstrated the problem of quantifying the mechanical contribution of rock bolts installed systematically around tunnels excavated in rock masses. Cai et al. [12] analyzed the interaction mechanism of the rock bolt and the soft rock mass according to their displacement variation under axial force. Guan et al. [13] studied the influence of the bolt properties on the reinforcement effect of surrounding rock. Skrzypkowski [14] characterized individual point resin and expansion rock bolt support effect in Polish ore mining. Kang et al. [15] concluded the mechanisms and factors resulting in bolt fracture through a close examination of fractured bolts obtained from underground chambers.

Although the research on bolt has been going on for more than a century, most of the research either studies the 
static response or dynamic response of a single bolt [16-24] or studies the supporting effect of bolt in the surrounding rock under static or dynamic load [25-30]. However, in practice, the bolt and surrounding rock are interacting, and the anchored rock mass is simultaneously subjected to both static and dynamic loads. Therefore, it is very meaningful to study the dynamic response of bolt in deep high ground stress surrounding rock. Under the current technical level, it is still impossible to carry out laboratory test or field in-situ test research on the stress characteristics of bolt in the current working condition. RFPA software is a numerical experiment method that can simulate the whole process of progressive rupture of materials [31]. RFPA software has been widely used to simulate the process of rock failure and engineering stability under various conditions [32-35].

Therefore, RFPA software is used to conduct in-depth discussion and research on the mechanical response characteristics of the surrounding rock and bolt of the deep chamber under dynamic load, in order to conduct a comprehensive analysis of the force state of bolt, and we expect to make some contributions to the development of bolt support technology. We hope our work can provide reference for the design and construction of underground chamber bolt support under the same or similar conditions.

\section{Numerical Model Design considering Dynamic Load}

2.1. Numerical Model Description. As shown in Figure 1, an underground chamber vertical section is analyzed according to the plane strain problem. The numerical model with bolts (WBNM) and the numerical model without bolt (NBNM) are established. The dimensions of two numerical models are $200 \mathrm{~mm} \times 200 \mathrm{~mm}$. A square underground chamber is excavated in the middle of the model, and the side length of this square underground chamber is $40 \mathrm{~mm} \times 40 \mathrm{~mm}$. The calculation area is divided into $400 \times 400$ quadrilateral isoparametric units. The mechanical parameters of these units are assumed to be assigned according to a Weibull distribution, and the values of physical and mechanical parameters are shown in Table 1 . The model dimensions of bolt are $1 \mathrm{~mm} \times 25 \mathrm{~mm}$. Eight bolts are arranged along the top and two sides of the numerical model, and the distance between the bolts is $5 \mathrm{~mm}$.

2.2. Loading Mode of the Underground Chamber. The loading methods of both numerical models are carried out according to the following two steps:

(1) First, the static loading is carried out to simulate the deep ground stress environment of surrounding rock. The bottom of the numerical model is fixed, and the top and both sides of the numerical model are subjected to the same static load. Assuming that the average self-weight of the overburden strata is $25 \mathrm{kN} / \mathrm{m}^{3}$ and the depth is $1000 \mathrm{~m}$, the constant static load of numerical model (marked $p_{S}$ ) is $25 \mathrm{MPa}$.

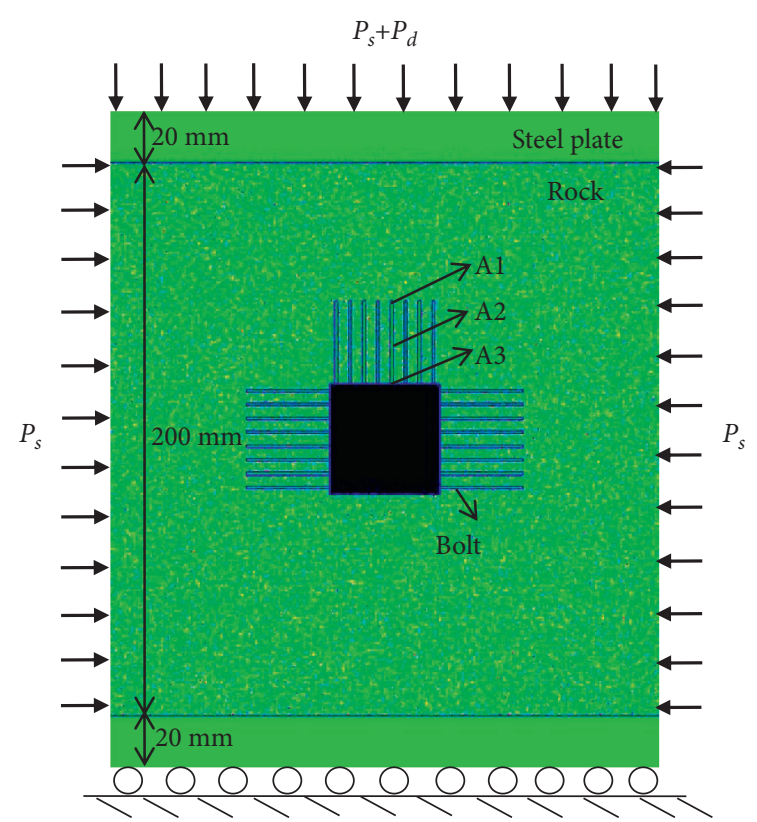

FIGURE 1: Numerical calculation model with a square underground chamber and loading method. The three points A1, A2, and A3 are located at the top, middle, and bottom of the bolt, respectively, $p_{S}$ stands for the static load, and $p_{d}$ is the meaning of dynamic load.

TABLE 1: Numerical model physical and mechanical parameters.

\begin{tabular}{lcc}
\hline Parameter & Rock & Bolt \\
\hline Inhomogeneous index & 3 & 50 \\
Strength (MPa) & 150 & 350 \\
Young's modulus (MPa) & 58000 & 210000 \\
Poisson's ratio & 0.25 & 0.27 \\
Density $\left(\mathrm{kg} / \mathrm{m}^{3}\right)$ & 2500 & 7800 \\
Friction angle $\left(^{\circ}\right)$ & 32.7 & 30 \\
\hline
\end{tabular}

(2) Second, the dynamic stress wave $p_{d}$ is applied to the calculation region to simulate the process of instability and failure of underground chamber surrounding rock with high ground stress due to a dynamic disturbance. To simplify the calculation, the dynamic disturbance is assumed to be a trapezoidal stress wave, as shown in Figure 2. The period of stress wave action is $3 \mu \mathrm{s}$, in which the period of both the ascending and descending segments is $1 \mu \mathrm{s}$ separately, and the amplitude of stress wave is $100 \mathrm{MPa}$.

\section{Analysis of Numerical Experiment Results}

3.1. AE Characteristics. The abscissa of all curves in this paper starts from loading step 150. At this time, the stress wave has not reached the bolt of the underground chamber roof.

Figure 3 shows the variation curves of $\mathrm{AE}$ count and $\mathrm{AE}$ accumulated count of two numerical models with the increase of loading step. Before the step reaches step 232, the $\mathrm{AE}$ count is sometimes absent and the $\mathrm{AE}$ accumulated count increases slowly in the numerical model without bolt (see Figure 3(a)). According to the failure diagram of the 


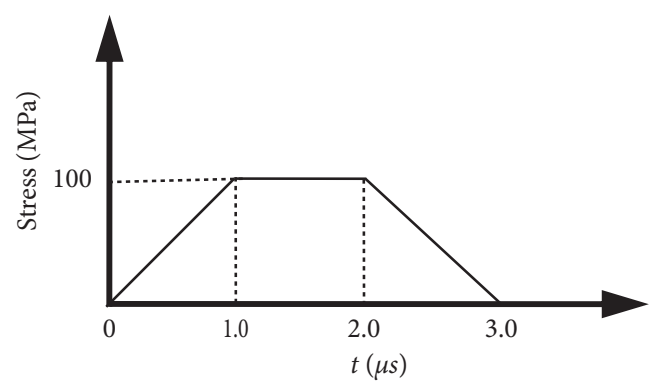

FIgURE 2: Dynamic stress waveforms on the model.

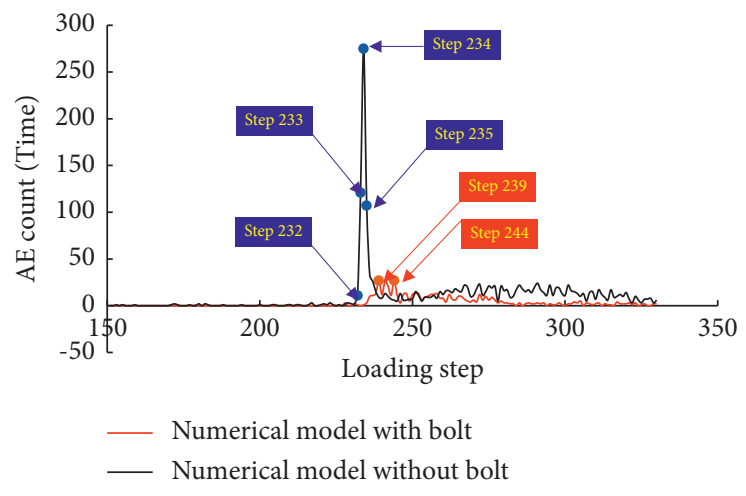

(a)

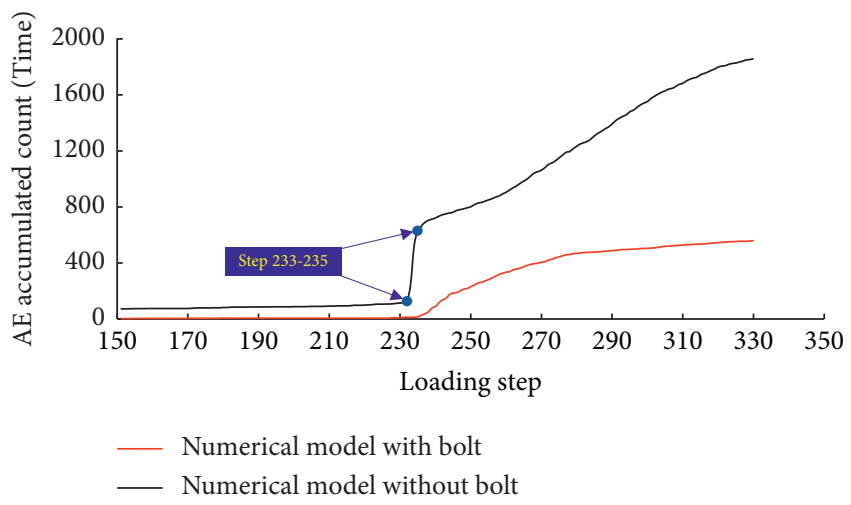

(b)

FIgURE 3: AE curve comparison of the two numerical models with bolt and without bolt. (a) AE count. (b) AE accumulated count.

numerical model (see Figure 4(a)), it can be seen that only a small number of units with weak strength around the underground chamber appear failure phenomenon first. From step 233 to 235 , the AE count increases sharply and reaches the maximum value 275 at step 234, and the curve of $\mathrm{AE}$ accumulated count shows an obvious jumping phenomenon. During this period, a large number of damaged units appear on the roof of the underground chamber (see Figures 4(b)-4(e)); that is, the roof of the underground chamber suddenly collapses in a large area at less time. This also shows that the destruction of the underground chamber roof under dynamic load is an instantaneous large-area collapse.

As shown in Figure 3(b), after AE accumulated curve of the numerical model without bolt jumps, the curve slope increases and the rate of unit fracture increases accordingly. On the contrary, the AE curve and AE accumulated curve of the numerical model with bolt have no obvious fluctuations, and there is no obvious jumping phenomenon. The $\mathrm{AE}$ count of the numerical model with bolt reaches the maximum value of 27 in step 239 and step 244, which is only $1 / 10$ of the maximum number of $\mathrm{AE}$ for the numerical model without bolt. During the entire loading process, the slope of $\mathrm{AE}$ accumulated count curve of the WBNM is lower than that of the NBNM curve, and the number of damaged units in the WBNM is far less than the number of damaged units in the NBNM under the same loading step. When the loading is over, the cumulative number of $\mathrm{AE}$ is 1859 in the $\mathrm{NBNM}$, and the cumulative number of AE is 559 in the
WBNM, which is about $1 / 3$ of the NBNM. In combination with Figure 5, it can be seen that the surrounding rock of the WBNM is very complete.

The white circle represents shear failure, and the red circle represents tensile failure in the AE diagram. Analyzing Figure 6(a), the AE diagram of the NBNM shows that the AE type is tensile when the surrounding rock is damaged, indicating that the surrounding rock occurs tensile failure under the action of external force. As shown in Figure 6(b), most units of the WBNM have occurred shear failure, only a few elements have occurred tensile failure, and the tensile failure occurs around these bolts in the roof, indicating that these bolts have exerted a tensile effect. The unit failure modes of the two numerical models are different.

Figure 7 is the change curves of $\mathrm{AE}$ energy and $\mathrm{AE}$ accumulated energy of the two numerical models. It can be seen from this figure that the change trends of the AE count and $\mathrm{AE}$ energy of two numerical models are basically the same. The AE energy of the WBNM reaches the maximum value of $0.486 \mathrm{MJ}$ in step 235 and $4.105 \mathrm{MJ}$ in step 293 for the NBNM. It can be seen that the maximum value of AE energy of the model without bolt is about 8.4 times of that of the numerical model with bolt. At the end of loading, the total energy released by the WBNM and NBNM is $7.662 \mathrm{MJ}$ and $80.699 \mathrm{MJ}$, respectively, which means that the total energy released by the model without bolt is about 10.5 times that of the numerical model with bolt.

During the whole loading process, the fluctuation amplitude of the AE energy curve of the WBNM is much 


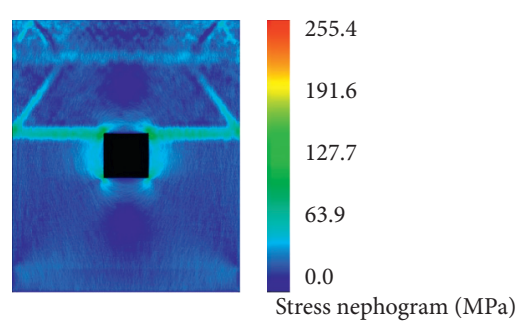

(a)

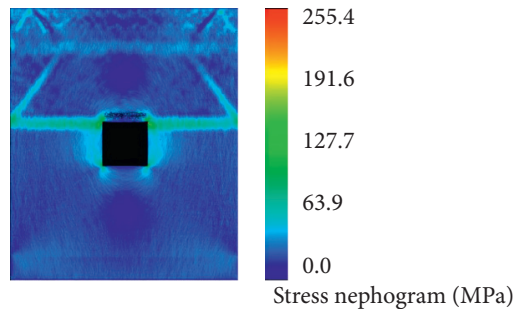

(d)

(b)
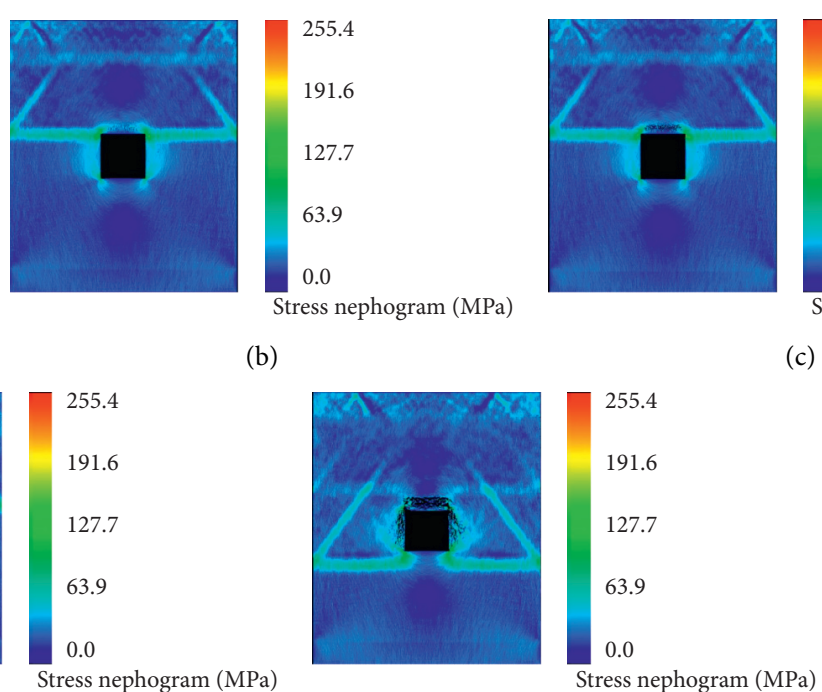

(e)

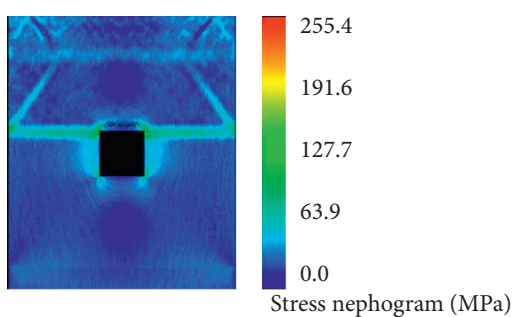

(c)

FIGURE 4: Fracture process of the numerical model without bolt. (a) (e) Loading step is 232, 233, 234, 235, and 330, respectively.
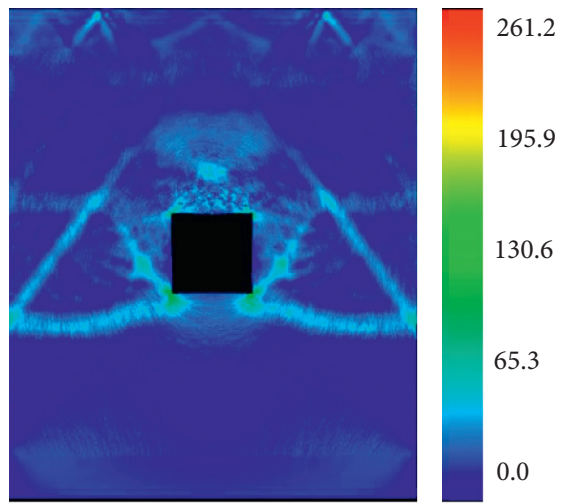

Stress nephogram $(\mathrm{MPa})$

FiguRE 5: Fracture pattern of the numerical model with bolt in loading step 330.

smaller than that of the NBNM, and the slope of the AE accumulated energy curve of the WBNM is also lower than that of the NBNM. It can be seen that the surrounding rock can absorb more energy after using bolt support, thus reducing the maximum value of energy and total energy released by surrounding rock, slowing down the rate of energy released by surrounding rock. Moreover, the time when the energy released by the WBNM reaches the maximum value is earlier than that of the NBNM, which indicates that the surrounding rock with bolt can absorb energy earlier and faster.

3.2. Stress Characteristics. The reason for points A1 and A2 of the two numerical models having peak value at different times is that the stress wave passes through this point (see Figure 8), which causes this point to bear more force than other points. As shown in Figure 8(a), there is no obvious peak in the stress curve at point A3 of the numerical model with bolt, the stress value fluctuates up and down, and the bolt is in the plastic deformation stage during this period of time. The main reason for the fluctuation of stress value is that the stress in the bolt is constantly adjusted with the increase of calculation step, and the repeated process of stretching and rebounding of the bolt is continuously produced, which is manifested as the continuous fluctuation of the stress value at point A3. In general, the stress of point $\mathrm{A} 3$ is lower than of points $\mathrm{A} 1$ and $\mathrm{A} 2$ on the bolt, indicating that the bolt absorbs stress wave energy and transfers the high-stress area to the deep part of surrounding rock, which reduces the stress on the surface of surrounding rock and protects the smoothness of roof surface.

When the stress wave propagates from top to bottom, the peak area of stress in surrounding rock continuously shifts downward, and the lower the peak value is, the smaller the stress is, as shown in Figure 8(b). The abovementioned phenomena show that the surrounding rock surface is damaged, the bearing capacity of rock mass is reduced, and the surrounding rock roof collapses in large area.

On the whole, the stress value at point A1 of the WBNM is roughly equivalent to the stress value of point $A 1$ of the NBNM during the entire loading process, see Figure 9(a). The stress values at points $\mathrm{A} 2$ and $\mathrm{A} 3$ of the WBNM are greater than the stress values at points $\mathrm{A} 2$ and $\mathrm{A} 3$ of the NBNM (see Figures 9(b) and 9(c)), which forebodes that the bolt in the WBNM absorbs a large amount of impact energy and bears greater force.

3.3. Displacement Characteristics. As shown in Figure 10(a), when the stress wave propagates from top to bottom, the displacement curves of points $\mathrm{A} 1$ and $\mathrm{A} 2$ where no obvious damage occurs in the numerical model without bolt present two stages, namely, a short rising period and a long quiet period. In addition, the curve slope in the ascending period is basically the same, and the displacement value in the quiet period is also basically the same at these two points. The 


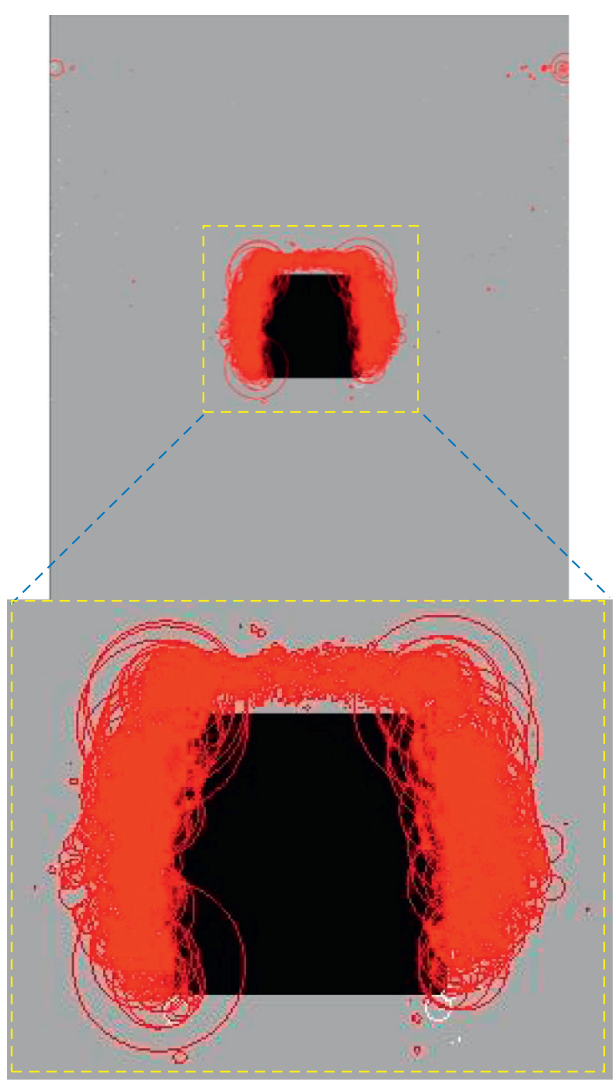

(a)

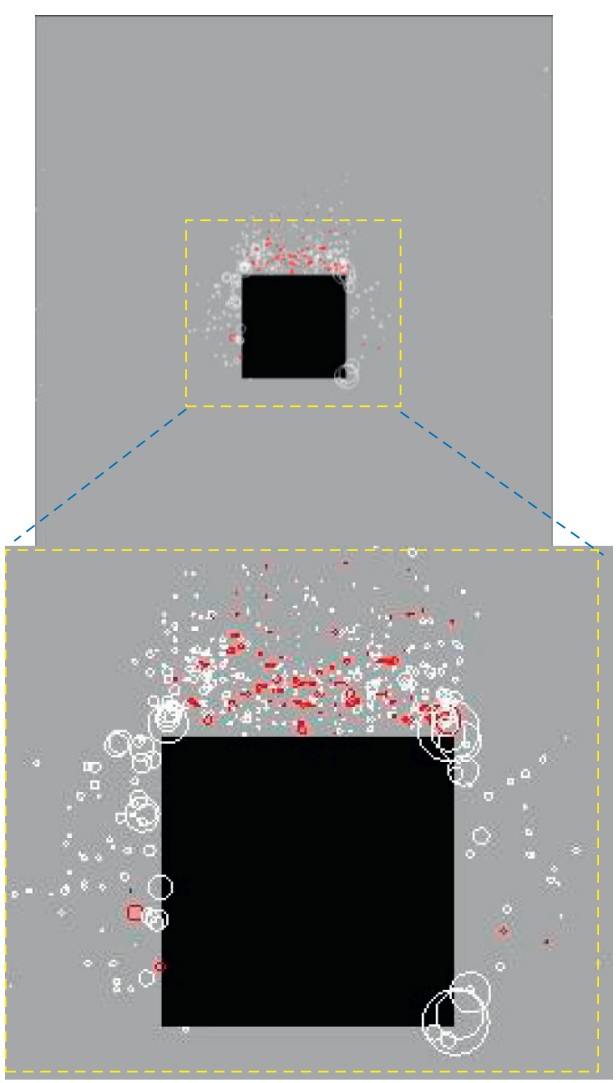

(b)

Figure 6: AE distribution around the underground chamber in the two numerical models. (a) Numerical model without bolt. (b) Numerical model with bolt.

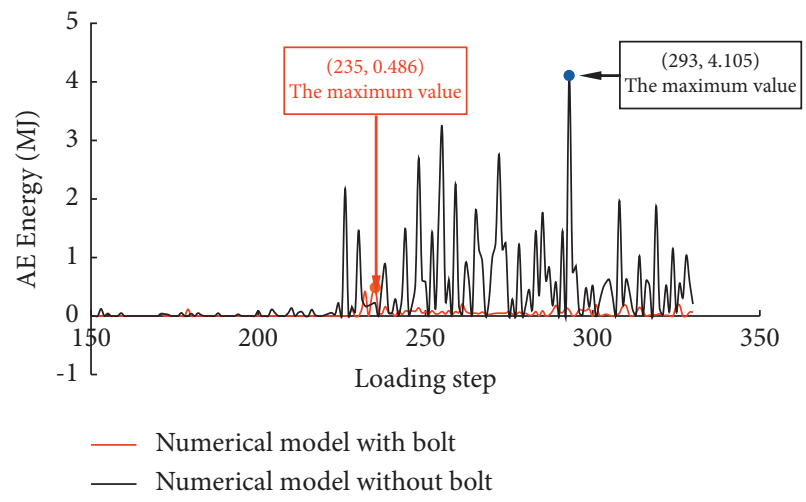

(a)

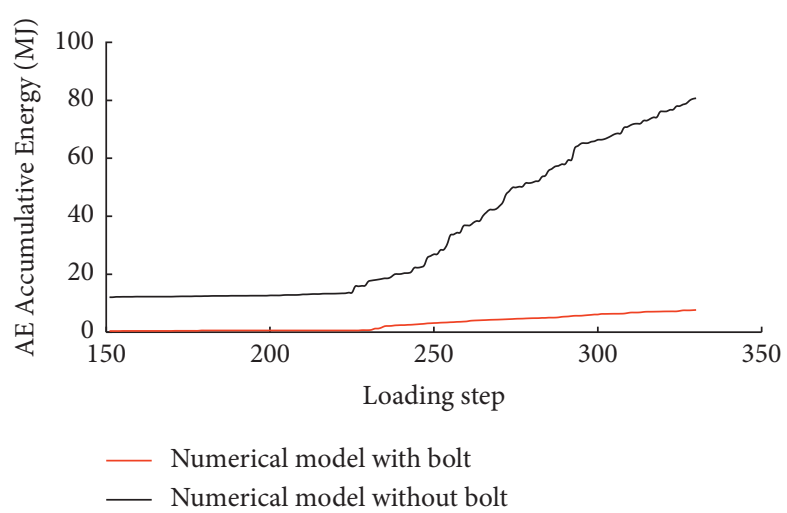

(b)

Figure 7: AE energy curve comparison of the two numerical models with bolt and without bolt. (a) AE energy. (b) AE accumulated energy.

displacement of point A3, located in the fracture zone of surrounding rock at the top of the underground chamber, shows a linear increase.

As shown in Figure 10(b), the displacement curves of points $\mathrm{A} 1$ and $\mathrm{A} 2$ in the underground chamber with bolt support where no obvious damage has occurred show three stages, i.e., rising period-quiet period-rising period. Moreover, the curve slope of the rising period of these two points is basically consistent, and the displacement value of the quiet period is also basically consistent. The displacement curve of point A3 at the top of the underground chamber presents two stages, i.e., the rising period and the quiet period. In the later stage of loading, the displacement values of points $\mathrm{A} 1$ and $\mathrm{A} 2$ rise, which can share the deformation of point A3. Finally, the displacement values of points $\mathrm{A} 1, \mathrm{~A} 2$, and $\mathrm{A} 3$ are approximately the same. The laws of the abovementioned curves' change show that, under the action of dynamic load, all parts of bolt in the chamber roof are deformed in time and bear the external force 


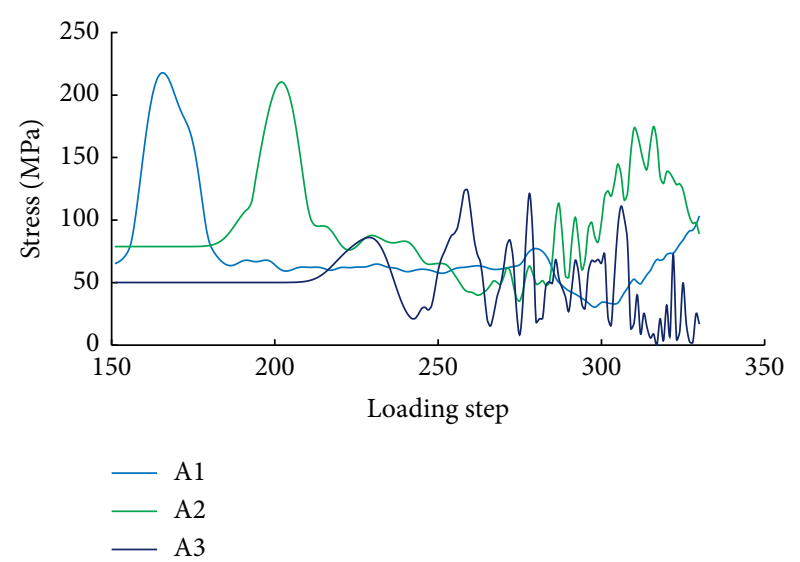

(a)

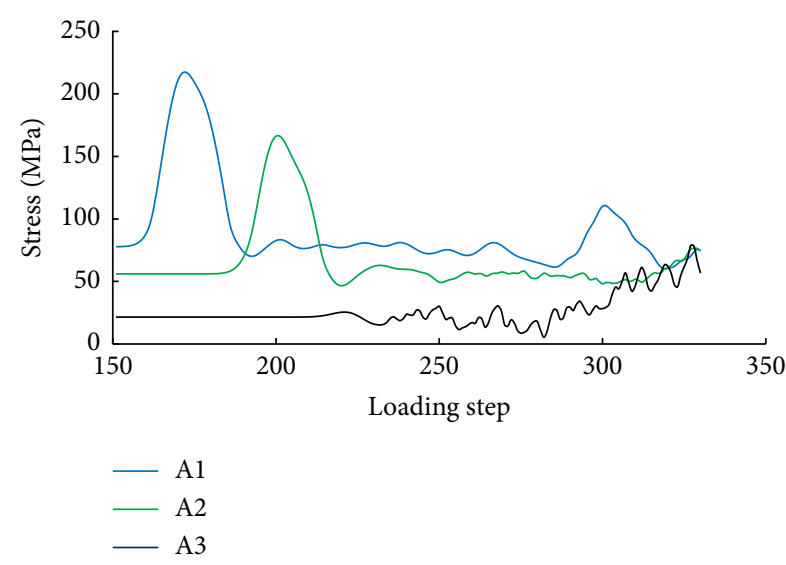

(b)

Figure 8: Stress characteristics of points A1, A2, and A3 in the two numerical models. (a) Numerical model without bolt. (b) Numerical model with bolt.

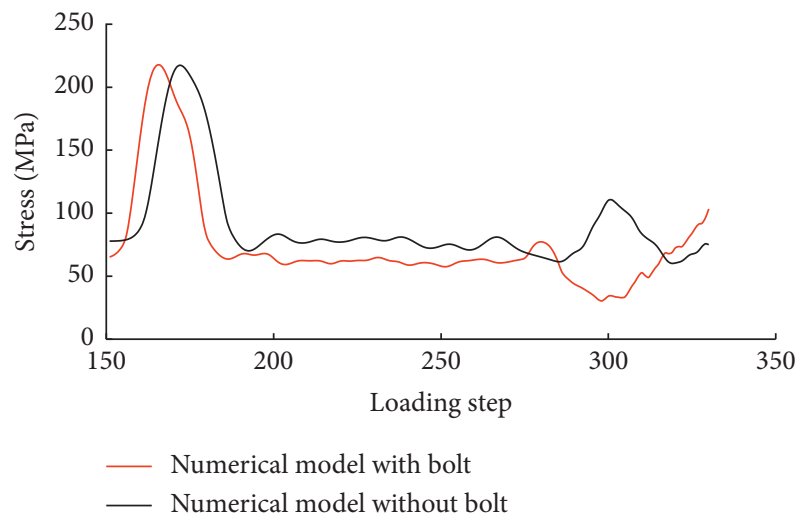

(a)

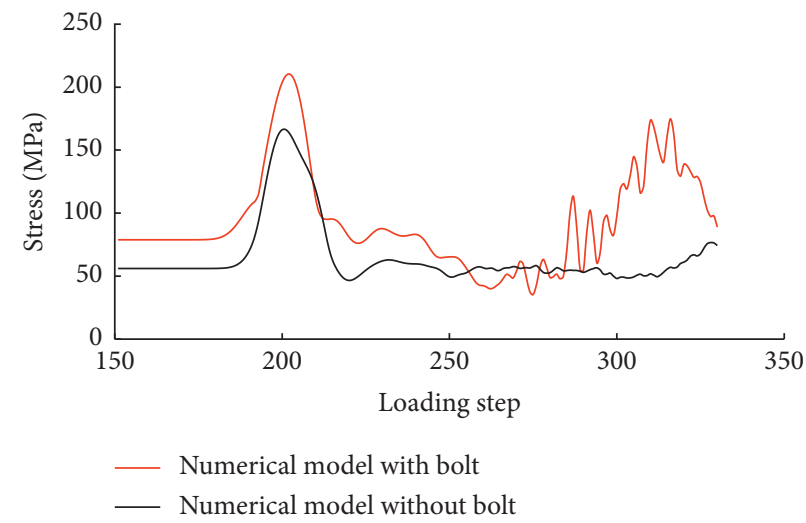

(b)

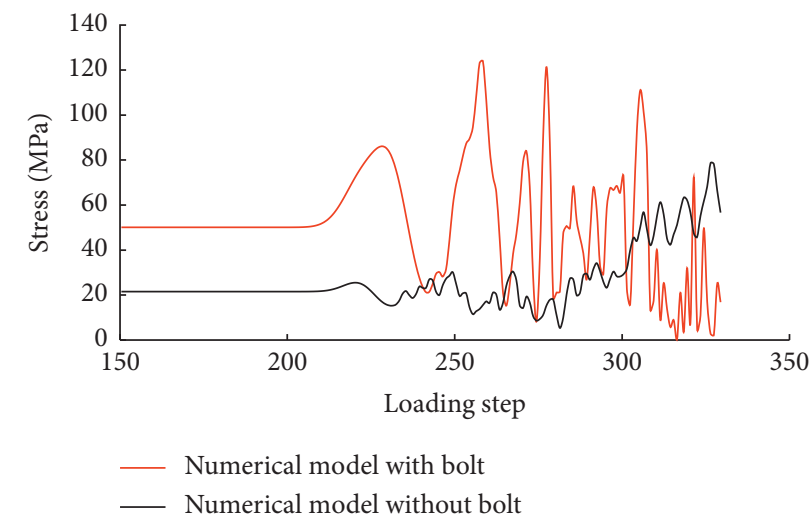

(c)

Figure 9: Stress comparison of the two numerical models at the same point. (a) Point A1. (b) Point A2 (c) Point A3.

together. The equivalent tensile deformation of the rod body has occurred in the last period of time, so as to prevent a certain part of the rod body from breaking due to excessive deformation.

It can also be seen from Figure 11 that the displacement values of points $\mathrm{A} 1$ and $\mathrm{A} 2$ in the undamaged area of the WBNM are greater than of the NMNM in the later loading stage, indicating that the tensile deformation of bolt is greater than the deformation of surrounding rock. During the entire loading process, the displacement value of point A3 in the failure area of the WBNM is smaller than that of the NBNM, and there is no unrestricted deformation. The reason is that the bolt exerts its tensile action to limit the displacement of the surrounding rock roof and prevent the roof from being damaged. 


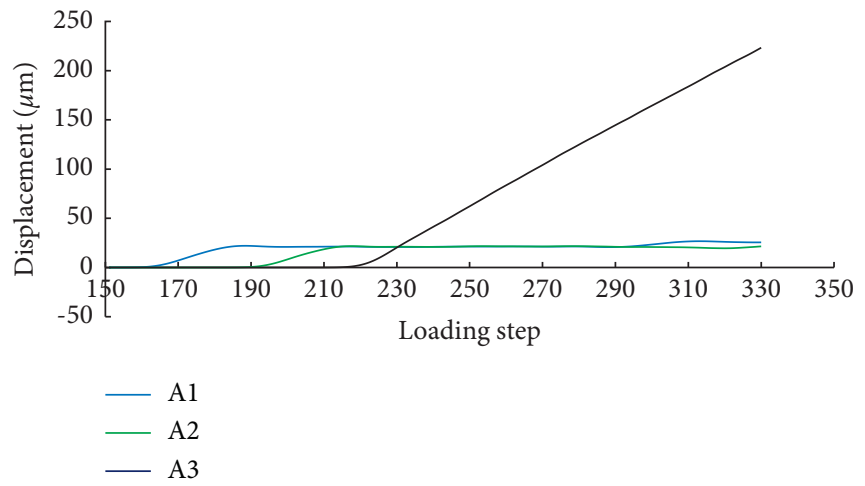

(a)

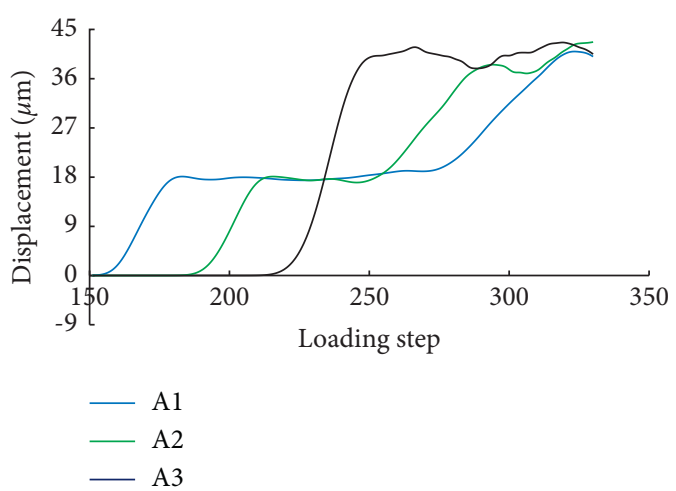

(b)

FIgURE 10: Displacement characteristics of points A1, A2, and A3 in the two numerical models. (a) Numerical model without bolt. (b) Numerical model with bolt.

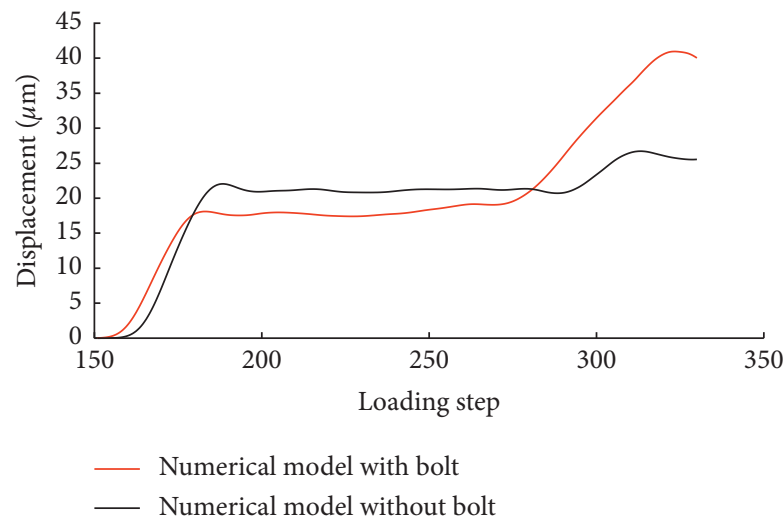

(a)

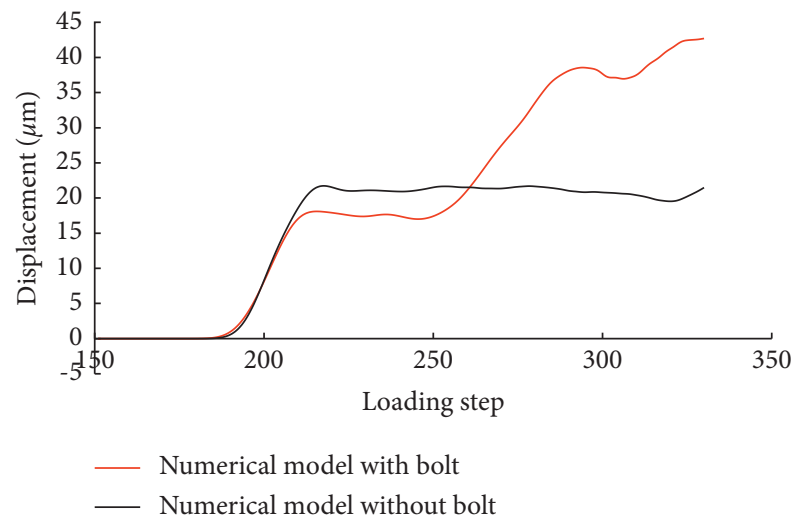

(b)

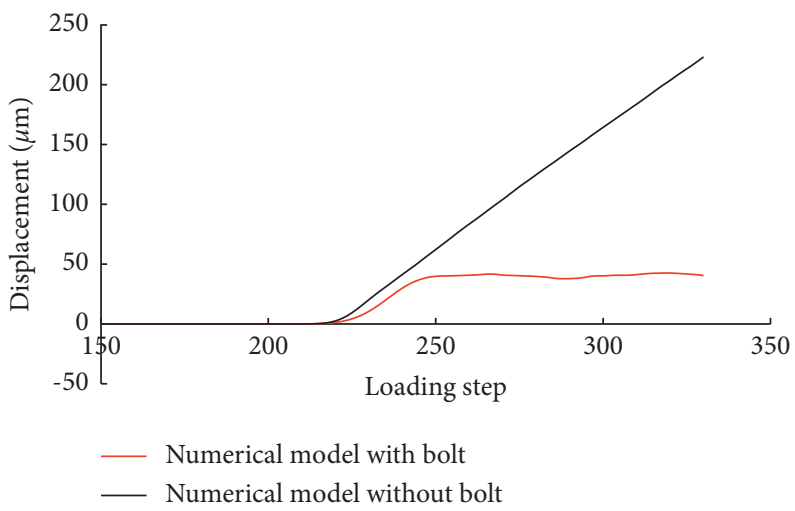

(c)

Figure 11: Displacement comparison of the two numerical models at the same point. (a) Point A1. (b) Point A2 (c) Point A3.

3.4. Discussion on Numerical Experiment Results. By comparing the numerical experiment results, it can be known that, under the same geological conditions and the same load, the roof of the underground chamber without bolt support appears large deformation and collapse, and the two sides of the underground chamber also have "V-shaped" failure areas (see Figure 4(e)). However, the underground chamber with bolt support only produces limited and controllable deformation, and the underground chamber is overall stable, which show that the surrounding rock of the underground chamber with bolt support has strong impact resistance.

Through the analysis of AE, displacement, and stress, it can be seen that, after the bolt is driven into surrounding rock, the bolt can absorb static load energy and impact energy through tensile deformation, enhance the bearing capacity of surrounding rock, and effectively control the deformation amount and deformation rate of surrounding 
rock. Moreover, the bolt has undertaken most of the impact force, which reduces the damage of rock mass and maintains the integrity of surrounding rock. Due to the existence of bolts in surrounding rock, the growth rate, maximum value, accumulated value of $\mathrm{AE}$ count, and $\mathrm{AE}$ energy have been reduced, and the main failure mode of surrounding rock has been changed; that is, the failure mode of most of units in surrounding rock is converted from tensile failure to shear failure.

\section{Conclusions}

(1) RFPA is used to analyze the failure mode of deep anchored surrounding rock under dynamic disturbance. Roof fall and rib spalling occur in the underground chamber without bolt support. In the underground chamber supported by bolt, bolt can transfer the high-stress area in the rock mass to the interior of rock mass, reduce the forces on surfaces of the roof and two sides in the underground chamber, and ensure the overall stability of surrounding rock.

(2) Bolt can greatly reduce the deformation and deformation rate of surrounding rock during the process of supporting. The reason why bolt is not broken after loading is that the displacement value of each part of bolt is basically the same. In this way, each part of bolt can bear external force to prevent individual parts from bearing greater force.

(3) A large number of tensile failure occurred around surrounding rock of the underground chamber without bolt support, and a small amount of shear failure occurred in surrounding rock of the underground chamber with bolt support, and the force mode of surrounding rock has changed obviously.

\section{Data Availability}

The data used to support the findings of this study are available from the corresponding author upon request.

\section{Conflicts of Interest}

The authors declare no conflicts of interest.

\section{Acknowledgments}

This study was supported by the National Natural Science Foundation of China (Nos. 51874162 and 52074142).

\section{References}

[1] C. F. Lee, W. Sijing, and Y. Zhifu, "Geotechnical aspects of rock tunnelling in China," Tunnelling and Underground Space Technology, vol. 11, no. 4, pp. 445-454, 1996.

[2] A. P. Rustan, "Micro-sequential contour blasting: how does it influence the surrounding rock mass?" Engineering Geology, vol. 49, no. 3, pp. 303-313, 2016.

[3] Y. X. Xiao, X. T. Feng, S. J. Li, G. L. Feng, and Y. Yu, "Rock mass failure mechanisms during the evolution process of rockbursts in tunnels," International Journal of Rock Mechanics and Mining Sciences, vol. 83, pp. 174-181, 2016.

[4] S. Ma, J. Nemcik, and N. Aziz, "An analytical model of fully grouted rock bolts subjected to tensile load," Construction and Building Materials, vol. 49, pp. 519-526, 2013.

[5] M. Muya, B. He, J. Wang, and G. Li, "Effects of rock bolting on stress distribution around tunnel using the elastoplastic model," Journal of China University of Geosciences, vol. 17, no. 4, pp. 337-354, 2006.

[6] Z.-h. Zhao, X.-j. Gao, Y.-l. Tan, and Q. Ma, “Theoretical and numerical study on reinforcing effect of rock-bolt through composite soft rock-mass," Journal of Central South University, vol. 25, no. 10, pp. 2512-2522, 2018.

[7] R. K. Goel, A. Swarup, and P. R. Sheorey, "Bolt length requirement in underground openings," International Journal of Rock Mechanics and Mining Sciences, vol. 44, no. 5, pp. 802-811, 2007.

[8] A. Pytlik, "Comparative shear tests of bolt rods under static and dynamic loading," Studia Geotechnica et Mechanica, vol. 42, no. 2, pp. 151-167, 2020.

[9] A. Fahimifar and M. Ranjbarnia, "Analytical approach for the design of active grouted rockbolts in tunnel stability based on convergence-confinement method," Tunnelling and Underground Space Technology, vol. 24, no. 4, pp. 363-375, 2009.

[10] X. Liu, Y. Li, F. Zhao, Y. Zhou, W. Wang, and S. Li, "Experimental research on mechanical and energy characteristics of reinforced rock under dynamic loading," Shock and Vibration, vol. 2019, Article ID 4356729, 11 pages, 2019.

[11] C. Carranza-Torres, "Analytical and numerical study of the mechanics of rockbolt reinforcement around tunnels in rock masses," Rock Mechanics and Rock Engineering, vol. 42, no. 2, pp. 175-228, 2009.

[12] Y. Cai, T. Esaki, and Y. Jiang, "An analytical model to predict axial load in grouted rock bolt for soft rock tunnelling," Tunnelling and Underground Space Technology, vol. 19, no. 6, pp. 607-618, 2004.

[13] Z. Guan, Y. Jiang, Y. Tanabasi, and H. Huang, "Reinforcement mechanics of passive bolts in conventional tunnelling," International Journal of Rock Mechanics and Mining Sciences, vol. 44, no. 4, pp. 625-636, 2007.

[14] K. Skrzypkowski, "Evaluation of rock bolt support for Polish Hard rock mines," E3S Web of Conferences.vol. 35, p. 8, 2018.

[15] H. Kang, Y. Wu, F. Gao, J. Lin, and P. Jiang, "Fracture characteristics in rock bolts in underground coal mine roadways," International Journal of Rock Mechanics and Mining Sciences, vol. 62, no. 6, pp. 105-112, 2013.

[16] L. St-Pierre, F. P. Hassani, P. H. Radziszewski, and J. Ouellet, "Development of a dynamic model for a cone bolt," International Journal of Rock Mechanics and Mining Sciences, vol. 46, no. 1, pp. 107-114, 2009.

[17] M. Cai and D. Champaigne, "Influence of bolt-grout bonding on MCB conebolt performance," International Journal of Rock Mechanics and Mining Sciences, vol. 49, pp. 165-175, 2012.

[18] C. C. Li, "Performance of D-bolts under static loading," Rock Mechanics and Rock Engineering, vol. 45, no. 2, pp. 183-192, 2012.

[19] C. C. Li and C. Doucet, "Performance of D-bolts under dynamic loading," Rock Mechanics and Rock Engineering, vol. 45, no. 2, pp. 193-204, 2012.

[20] A. Ansell, "Laboratory testing of a new type of energy absorbing rock bolt," Tunnelling and Underground Space Technology, vol. 20, no. 4, pp. 291-300, 2005. 
[21] A. Ansell, "Dynamic testing of steel for a new type of energy absorbing rock bolt," Journal of Constructional Steel Research, vol. 62, no. 5, pp. 501-512, 2006.

[22] X. Z. Wu, G. Wang, and Y. J. Jiang, "Mechanism of CTC-yield bolts and its experimental research," Chinese Journal of Geotechnical Engineering, vol. 37, no. 1, pp. 139-147, 2015.

[23] G. Wang, X. Wu, Y. Jiang, N. Huang, and S. Wang, "Quasistatic laboratory testing of a new rock bolt for energy-absorbing applications," Tunnelling and Underground Space Technology, vol. 38, pp. 122-128, 2013.

[24] M. He, W. Gong, J. Wang et al., "Development of a novel energy-absorbing bolt with extraordinarily large elongation and constant resistance," International Journal of Rock Mechanics and Mining Sciences, vol. 67, no. 1, pp. 29-42, 2014.

[25] C. Chunlin Li, "A new energy-absorbing bolt for rock support in high stress rock masses," International Journal of Rock Mechanics and Mining Sciences, vol. 47, no. 3, pp. 396-404, 2010.

[26] G. Wang, X. Z. Wu, and Y. J. Jiang, "Coupling model and calculation method of yielding bolt and rockmass," Rock and Soil Mechanics, vol. 35, no. 3, pp. 887-895, 2014.

[27] T. R. Stacey, "Addressing the consequences of dynamic rock failure in underground excavations," Rock Mechanics and Rock Engineering, vol. 49, no. 10, pp. 4091-4101, 2016.

[28] L. Chen, G. Sheng, and G. Chen, "Investigation of impact dynamics of roof bolting with passive friction control," International Journal of Rock Mechanics and Mining Sciences, vol. 70, no. 9, pp. 559-568, 2014.

[29] M. Salcher and R. Bertuzzi, "Results of pull tests of rock bolts and cable bolts in Sydney sandstone and shale," Tunnelling and Underground Space Technology, vol. 74, pp. 60-70, 2018.

[30] A. Ansell, "In situ testing of young shotcrete subjected to vibrations from blasting," Tunnelling and Underground Space Technology, vol. 19, no. 6, pp. 587-596, 2004.

[31] C. A. Tang and P. K. Kaiser, "Numerical simulation of cumulative damage and seismic energy release during brittle rock failure-part I: fundamentals," International Journal of Rock Mechanics and Mining Sciences, vol. 35, no. 2, pp. 113-121, 1998.

[32] C. Tang, "Numerical simulation of progressive rock failure and associated seismicity," International Journal of Rock Mechanics and Mining Sciences, vol. 34, no. 2, pp. 249-261, 1997.

[33] P. Jia and C. A. Tang, "Numerical study on failure mechanism of tunnel in jointed rock mass," Tunnelling and Underground Space Technology, vol. 23, no. 5, pp. 500-507, 2008.

[34] C. A. Tang, W. T. Yang, and Y. F. Fu, "A new approach to numerical method of modelling geological processes and rock engineering problems-continuum to discontinuum and linearity to nonlinearity," Engineering Geology, vol. 49, no. 3-4, pp. 207-214, 1998.

[35] C. A. Tang and Y. F. Fu, Numerical Test on Rock Failure Process, Science Press, Beijing, China, 2003. 